Fo hed two or three liquid focel eracuations during the ar, and was not worse at night. He had taken grain-doses of quinine, with an efforrescent ammonis mirture, during the day.

Nov. 30th. He took tro calomel and opinm pills in the night, on account of restlessness. He had only one small liquid motion during the night. The abdomen was more tender, and more generally distended. The countenance was dejected. The pulse was weak, but not more rapid than yesterday. He had no sickness. Wo determined to upply turpentine stupes to the abdomen; to give port wine negus, good broth, and a dose of castor oil and laudanum; and to repeat the injection in the evening, if we then found him in a fit state to bear it. $\mathrm{He}$ appeared to be gradually sinking; and yet he had evidently a passage through the canal sufficient for fluid to pass ; and the golid obstruction (perhaps a large gall-stone) scemed almost within reach of manipulation.

In the evening, we found him so much more feeble that we declined further interference as hopeless, merely giving some opium to ease his pain. He died at about nive o'clock the following morning.

No post mortem examination was allowed.

It was unfortunate that in this case I could not obtain leave to examine the body after death, for without this it has lost chief of its practical interest. I offered the wife every possible inducement to allow it, but failed to make the slightest impres. sion upon her mind in favour of what I most urgently requested.

[To be continued.]

\section{CASE OF IMPERFORATE RECTUM, WITH MALFORMATION OF THE COLON.}

By Thomas O'Connor, Esq., March.

Mrs. A. B., the wife of a labourer, was delivered of an apparently healthy child. Five days afterwards, I was consulted by the mother, who informed mo that her infant's bowels bad never been relieved. I passed my finger into the rectum, and found that it terminated, at about three-fourths of an inch from the anus, in a cul-de-sac. Having consulted with a neighbouring surgeon, $I$ determined on dividing the obstructing membrane. This I effected with a probe-pointed bistoury, but failed to reach the bowel. I subsequently dilated this opening with a full-sized common bougie, and after that with a small rectum-bougie, passing these instruments fully two inches without resistance. Ultimately, the aperture was large enough to admit the little finger; but as no fluctuation, such as would indicate the proximity of a bowrel, could be detected, $I$ ab. stained from further operative proceedings. As after events proved, it was well that I did so, as I could not have reached the bowel.

The child lived until the sixteenth or seventeenth day, when it died, with an enormously distended abdomen. It took daily, for the first twelve days, a fair quantity of food at intervals of four or tive hours, and rejected it by vomiting, copiously tinged with bile, after having retained it about half-an-hour. The urine passed was excessive in quantity, and highly ammoniacal. The complexion, up to within the last two or three days of life, was clear, and might be considered consistent with perfect health.

A post mortem examination revealed the following anatomical conditions. The anus was normal, with its sphincter muscle well developed. The rectum, as far as it went, was sufficiently capacious, torminating, as I have stated, in an impassable pouch at about three-quarters of an inch from the anus. The posterior surface of this pouch was fixed to the tip of the coccyr by a granular substance, resembling in texture the mesenteric glands. The cæcum occupied its normal anatomical position in the right iliac fossa. The ascending colon, which received the ileum in its usual position, pursued its normal route; so did the transverse colon. There could hardly be said to be any descending colon; for at the upper border of the left kidney it became suddenly contracted, as if a ligature had been cast around; it here degenerated into a fibrous cord which, descending and diverging from its course towards the promon. tory of the sacrum, terminated at that point by uniting and identifying itself with the iliac fascia. The bladder, which was empty, was unusually large, capable of containing four onnces of flaid, and placed not in the pelvis but in the abdomen, $i . e$. in the left iliac fossa, occupying the place assigned, in the narmal position of parts, to the sigmoid flexure of the colon. The urethre was necessarily more than double it natural length, measuring two inches and a-half, and large enough to admit a full-sized cathotor. The true pelvis was 80 contracted as to be scarcely capable of lodging a pigeon's egs.

An opening into the left iliac fossa, had I advised suoh proceeding, which I did not, would have failed to give relief, as the large intestine, as has been stated, degenerated into a cord impervious at a point corresponding to the upper border of the left kidney. The only practical hint which I can see in connexion with the case, and which entitles it to notice at all, is the following : If in imperforate anus, or suspected deficient rectum, the surgeon should feel it his duty to recommend an opening into the left iliac fossa for the purpose of establishing an artificial anus, it will be well to bear in mind that nature sometimes, in her erratic humour, leaves out the whole of the descending colon, or substitutes for it a shrivelled and impervious fibrous cord.

OBSERVATIONS ON THE MORBID ANATOMY, PATHOLOGY, AND DETERMINING CAUSE OF EMPHYSEMA OF THE LUNGS.

By A. T. H. WATERS, M.R.C.P., Physician to the Liverpool Northern Hospital ; Lecturer on Anatomy, Physiology, and Pathology, in the Liverpool Royal Infirmary School of Medicine.

[Tead brfure the Royal Medical and Chiruroical Society.]

Part I.

The different kinds of Enphysema. Vesicular Emphysema; its various forms. Mlodes of Preparation of Lung Tissue for examination. Changes which take place in the Air.Sacs in the different Stages of the Disease. Condition of the Blood.Vessels; of the Bronchial Tules. Is the Disease attended with any Degeneration of Tissue? Interlobular Emphyscina.

[Continued from p. 913.]

Pulyonary emphysema is of two kinds :-I. Vesicular Emphysema; Ir. Intcrlobular Emphysema. The first is by far the most frequent and most important affection. I have rarely seen the second, except in advanced cases of the first kind.

I. Pulmonary Vesicular Emphysema exists in three forms, not differing in their minute anatomical arrangement, nor yet probably in their essential nature, but only in the extent to which they involve the lung. We have, firstly, that which is the most partial, and confined to a few air-sacs or to a single lobulette; secondly, that in which the whole of a lobule is affected; and thirdly, that in which the whole of one lobe of a lung, or, more frequently, the whole of the lung itself, is involved in the disease.

1. The first form of the disease, or partial lobular emphy. sema, is not often seen as an independent affection; but in lungs in which the second form exists, we occasionally meet with small patches of dilated air-sacs, especially along the margins of the lobes-patches which clearly only involve a few air sacs, or at most, a single lubulette. These portions resemble enlarged vesicles; and, as pointed out by M. Lombard of Genev\& many years ago, have very much the appearauce of the vesicles of pemphigus. They push outwards the pleura, so as to raise it above the level of the surrounding lung.tissue. They are not simple elevations of the pleura, as may be distinctly seen in injected preparations, when the blood-vessels belonging to the air-sacs may be seen ramifying beneath the pleura. Sometimes these partial emphysematous patches are seen extending for some distance along the margin of the base of the lung, and they have then an appearance very like that of a row of beads.

2. The second form, or lobular emphysema, is that most frequently met with; in fact, in the majority of post mortem examinations I have scen, since my attention has been directed to this subject, I have found this form of emphysema more or less prevailing. It involves one or more lobules in differen parts of the lung, and is more especially found along the margins of the base of the lung, the anterior border, and apex of the lung. This is the kind of emphysema so frequently found in cases of phthisis; I have also witnessed it in cases of pneumonia where the lung has become consolidated; and 
in ono inctenos of this latter lind the exphreema had all the appearances of having been recently producud.

In this form of emphysema it is easy to trace the difierent divisions of the lung; the boundary wall of the lobules has not given way, and there is no interlobular emphyseme, except in some cases, and to a partial extent. Again, it is by no means essential that all the air-sacs in an affected lobule shall be equally dilated; the most superficial ones, those especially beneath the pleura, suffer most. At the same time, it must be remarked that this unequal dilatation is sometimes more appa. rent than real, resulting from the mode of preparation to which the tissue has been subjected; viz inflation and desiccation. During the process of drying, the air-sacs farthest from the surface collapse most, and thus they have the appearance of being smaller than they really are.

The emphysematous lobnles are seen on the surface of the lung, protruding beyond the level of the surrounding tissue, and along the margins of the lobes they often form projections of considerable size, in some instances becoming developed into the so-called appendages.

3. The third form of pulmonary vesicular emphysema is that which may be called lobar. As far as my observations go, it more frequently attacks both lungs than one, and as well the lower as the upper lobes. It constitutes a most formidable affection, and often destroys life at an early period. The cases in which I have had an opportunity of witnessing the disease after death, have been in persons at adult age. Its features are very characteristic, and it is easily recognised during life. It consists of an emphysema of the whole pulmonary tissue of a lobe, or lung. The lung-substance has a peculiar doughy feel, and a colour very closely resembling that of a calf's lung The whole organ is increased in bulk, and may be inflated to a very large size. It presents when inflated, for the most part, a perfectly smooth and level surface, except in those cases where portions of collapsed lung exist; or where portions of lung ex. treniely emphysematous form projections or appendages. The ontlines of the lobules cannot be distinctly seen, in cousequence of the rupture of their boundary walls having given rise to the production of interlobular emphysema. The air may be pressed Iaterally from one lobule to another, and there is a want of healthy crepitation throughout the lung.

In examining the emplysematous lung-tissue to ascertain the anatomical changes of which it is the seat, I have adopted the same methods of preparation which I have made use of for

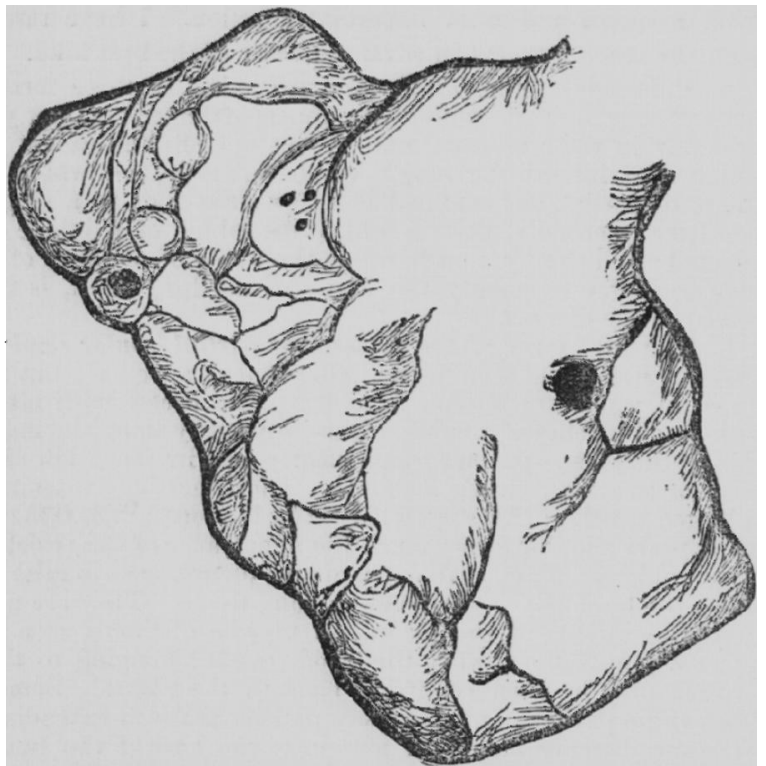

Fig. 5.-Air-sacs of a piece of emphysematons lung, injected, inflated, and dried. The lung from which the piece was taken was emphysomatous along its margins. The piece Tas taken from tho marin. It shows dilatation of the air-sacs moro or less oblite margin. Il shows dllatation of ho alr-sacs, more or less obliteration orthe alveoll, and silght por the al the perrorations. The alr-sacs in the ploce of lung examined varied in diameter from 1-20th to 1 -s0th of an inch-being more
than double their ordinary size in heal th.

the examination of the healthy organ: viz., first, inflation through a bronchial tube, and subsequent desiccation; and injection of the blood-ressels with a coloured solution of gelatine, followed by inflation and desiccation. If we examine pieces of lung, which have been prepared in either of these
Tase, nuder difierent degrees of development of emp breems, wo are enabled to asoertain the exact condition of the pulmonary tissue in the progressive stages of the affection, and the extent to which it has departed from the normal type.

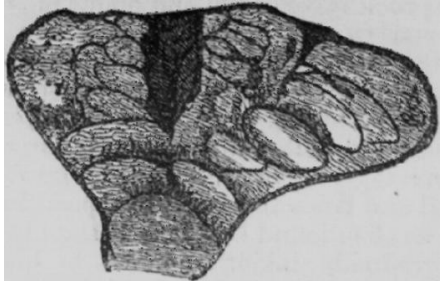

Fig 8-8lice of emphysematous lung in the earier stage of the disere The black spots air-sacs. (T'aken by means of the camera luciás.)

pletely obliterated, so as to give a regular and smooth appearance to the inner surface of the air-seos, instead of the honer-

g. 6.-Air-sacs from the same lung as Fig. 5, but not emphysematous. The alveoli are shewn with their septs vell marked. The diameter of the gacs in the part examined raried from 1-45th to . 0 th of an inch. Figs. 5 and 6 were both taken by means of the camera lucida, and the same magnifying power was used in botb. They therefore shew the relatire sizes of healthy and emplysems.

In the early stages of the disease we recognise a simple dilatation of the air-sacs, an increase in the size of the alveoli, a diminution in the height of the alveolar walls, which, yielding with the distending cavities, become partially obliter-
ated. As the disease progresses, the air.sacs become stil more distended, and the alveolar walls in some instances com

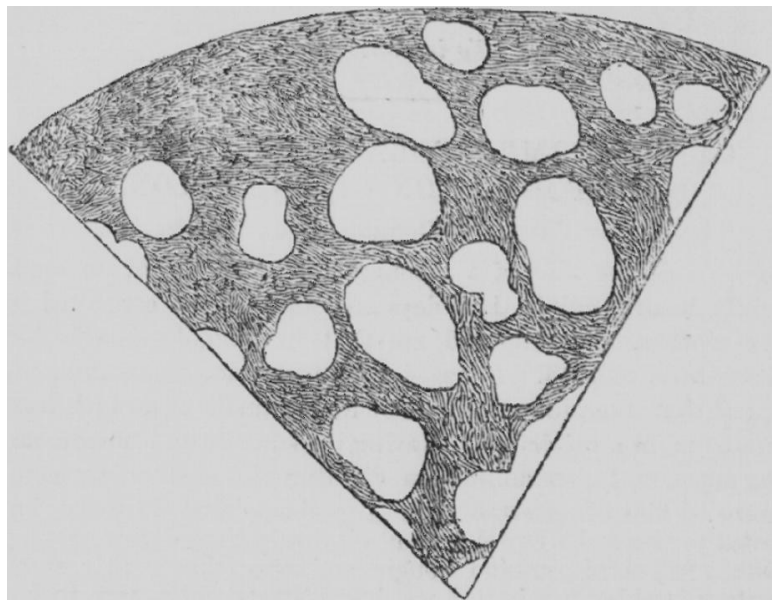

Fig. 7.-A slice of healthy lung-tissue. It shows the openings of the divided air-sacs, and the walls separating them, in a healthy condition. No perforations are seen. (Takeu by means of the camera lucida)

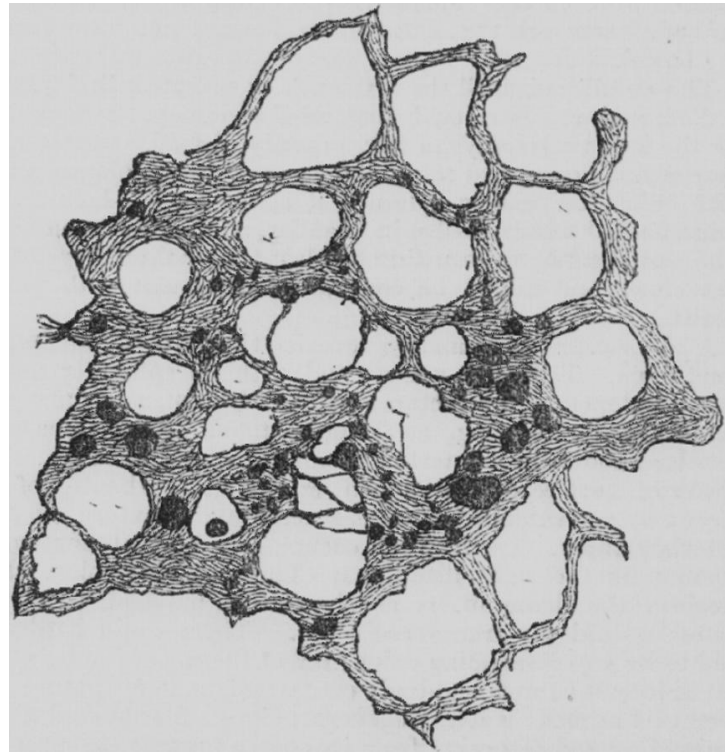


combed appearance characteristio of their narmal state. (See Figs. 5 and 6.) This distension of the air-sacs is necessarily attended with a divergenoe of the elastic fibres which enter into their composition, and with a general thinning of their wallscondition whioh prepares the way for the next stage in the pregress of the disease; viz., a perforation of the walls themselves. This, at first, is but slight; here and there a circular

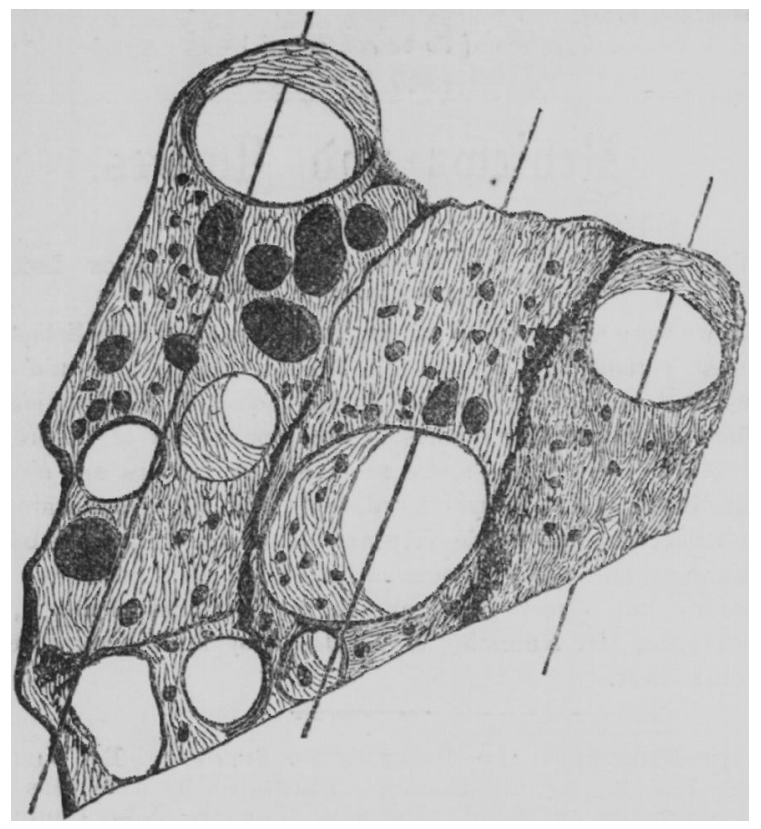

Fig. 9.-Air-sacs of emphysematous lung, as seen through dissecting microscope. The bristles are passed through the sacs. 'I'be upper walls of two, and the lower wall of one air-sac, are seen
with their perforntions.

or oval opening may be seen in the membrane; as the disease progresses, these openings become more numerous and larger; in some instances, the whole of the walls of the air-sacs and the septs of the alveoli being perfectly riddled with small openings, so that a horizontal section of the lung-substance has a general cribriform appearance. These openings are for the most part either circular or slightly oval. They exist in all parts of the walls, and are often seen in the septa between the alveoli, before the air-sacs are sufficiently distended to obliterate the septa. (See Figs. 7, 8, and 0.)

[To be continued.]

\section{Cransactions of 算rametbes.}

\section{READING BRANCH.}

TRANSACTIONS OF THE READING PATHOLOGICAT BOCIETY: ANNOAL RETROSPECTIVE ADDRESS.

By Nathantel Crisp, Esq., Swallowfield.

[Continued from p. 941.]

IV.-Genito-Urivary Systeyr.

Disease of Suprarenal Capsules. Mr. Hanninson read a case of diseaso of the suprarenal capsules with bronzed skin. The subject, a man 35 years of age, had worked for more than half his life in a biscuit factory, but was not much exposed to alternations in temperature. At different periods during his lifetime he had suffered from pleurisy, fever, and glandular affections; and although large framed, did not appear to bo a strong man. In May, 1858, he had several ulcers on his leg, which, in healing, left peculiarly dark cicatrices. During Christmas 1850, he suffered from bronchial affection, embarrassed breathing, and profuse perspiration. In the autumn of the same year, the skin of his forehead began to assume a dusky hue; and this cutaneous alteration progressed steadily over the whole body; weakness increased; and he died, apparently from exhaustion, in 1860, having been laid up completely for four months.

The following conditions were observed in a post mortem examination : little if any emaciation; the dusky hue of the skin lighter than during life; a tuberculous condition of the lungs; the heart small; the mesentorio glands enlurged; the right suprarenal capsule nearly one mues of tuberenlar de. posit, weighing three drachms; the corresponding kidner larger then usual and containing a scrofulons abseces; the left suprarenal capsule one tuberculous mass, weighing seven drachms and a half.

Mr. Harrinson referred to the supposed tuberculous nature of this disease, and also to the fact that the suprarenal cap. sules may be diseased without bronzing the skin, and vice vered. But why such a state of the skin should be induced by affections of the capsules, is as yet an undecided question. In some reniarks on this disease by Dr. Wilks, he considers that, 28 the discoloration of the skin only occurs in very chronic cases, it is always associated with the last degrees of alteration which the capsules undergo. This was hardly the case in this in. stance; the bronzed shin had existed for some months, bnt the capsules slowed no signs of degeneration into chalky masses; in fact, one was not completely destroyed by disease. Are we to suppose that disease of the capsules had existed for two years, about which time the alteration in the skin first declared itself in the peculiarly dark cicatrices of healed ulcers? or rather, were not the ulcered leg with its sequences due to the commencement of a disease, not arising from the suprarenal capsules, but from the blood itself? for it appears that the white corpuscles of tho blood are in excess in this class of cases. It has also been observed that cancerous disease invading the capsules is frequently associated with on altered condition of the skin. That some alteration of the function and structure of the capsules coexists with bronzed slin, we may allow; but not that such alteration is the cause of the disease, which appears so much allied to tubercle in its nature. We need much more information before we shall be able to decide this question; and even if it should be ultimately proved that the disease does spring directly from the capsules, we shall still have to learn much before we can discover its cure. The spleen, another organ about the use of which we are still in the dark, is, it now appears, liable to a peculiar affection depending upon the deposit of an opaque lardaceous material in isolated patches. Together with this are associated enlargement of one or more groups of lymphatic glands, and the most extreme aummia and prostration soon followed by death; the blood, in these cases, seeming to be deficient in red corpuscles. For a more full account of this disease, I must refer you to Guy's Hospital Reports ; this affection, ancemia lymphatica, as it is called by Dr. Wilks, possesses, I think, many points of interesting similarity to Addison's disease; both are rare; are characterised by an altered condition of the blood; are fatal in their tendency; seem allied in some way with the tubercular diathesis; are associated with extreme prostration and the disorganistion of portions of our frame, the use of which is obscure.

Atrophied Kidney. Mr. ORD presented an atrophied kidney, from a man who suddenly died comatose, after having recovered from an attack of jaundice probably dependent on uræmic poisoning. Urea injected into the veins appears to engender air; and Mr. George May had formerly attended this man for dyspnœa, from which be recorered after expectorating peculiarly frothy mucus.

Mr. MAY exhibited specimens of encysted vesical calculus and cellulo-fibrous tumour of the labium.

\section{Y.-Matignant Diseases.}

Fungus Hamatodes of the Kilney. Mr. WaLford related the purticulars of a very interesting case of fungus homatodes of the bidney occurring in a child 3 years and 8 months old, who had been under his care for about two months, his parents thinking that he was dropsical. When first seen, the abdominal cavity was distended with fluid, the lower extremities were cdematous, and a solid tumour, tender on pressure, was detected, leading to the supnosition that malignant disease of the liver existed, and that the case was hopeless. The patient rapidly grew worse, suffered much from extreme restlessness at night, and shortly died. On a post mortem examination, the abdominal cavity was founil to contain three or four pints of serous and bloody fluid. A tumour was discovered, extending and adherent to, but separabie from, the liver. This gronth was found to be connected with the right kidney; it weighed from three to four pounds, pressed upon the portal veins, and consisted of a mass of medullary encephaloid cancer; the kidney itself was pale but healthy. No malignant diseese could bo discovered in any other organ.

MIr. Walford quoted various authors, amongst them Rokitansky, who consider the kidney to be often the seat of malig- 